\title{
Mixed connective tissue disease presenting as a left sided pleural effusion
}

\author{
Y Ilan, A Ben-Yehuda, E Okon, R Breuer
}

Department of Medicine A,

Hadassah University Hospital, Jerusalem, Israel

Y Ilan

A Ben-Yehuda

Department of

Pathology,

Hadassah University

Hospital, Jerusalem,

Israel

E Okon

Pulmonary Unit,

Hadassah University

Hospital, Jerusalem

Israel

R Breuer

Correspondence to: Dr Y Ilan,

Department of Medicine A,

Hadassah University

Hospital, POB 12000

Accepted for publication

17 December 1991
Jerusalem, Israel 91120

\begin{abstract}
Mixed connective tissue disease (MCTD) usually occurs in women aged 13-50 years. Pleural effusion is rarely the presenting feature of this disease. The case is reported here of a male patient with MCTD who presented at the age of 79 years with a left sided pleural effusion.
\end{abstract}

(Ann Rheum Dis 1992; 51: 1157-1158)

Mixed connective tissue disease (MCTD) is a syndrome characterised by a combination of clinical features similar to those of systemic lupus erythematosus, scleroderma, polymyositis, and rheumatoid arthritis, and an unusually high titre of circulating antibodies to ribonucleoprotein. ${ }^{1}$

The mean age of presentation is 31.9 years and $80 \%$ of patients are women. ${ }^{12}$ Pulmonary disease is usually interstitial and occurs in $80 \%$ of patients with MCTD.

The case is reported of a 79 year old man with left sided pleural effusion as a result of MCTD.

\section{Case report}

A 79 year old white man presented with a three month history of dyspnoea on exertion, weakness, and pleural effusion. He had mild noninsulin dependent diabetes mellitus and benign hypertrophy of the prostate. He was not aware of any cardiopulmonary disease.

On physical examination the patient had

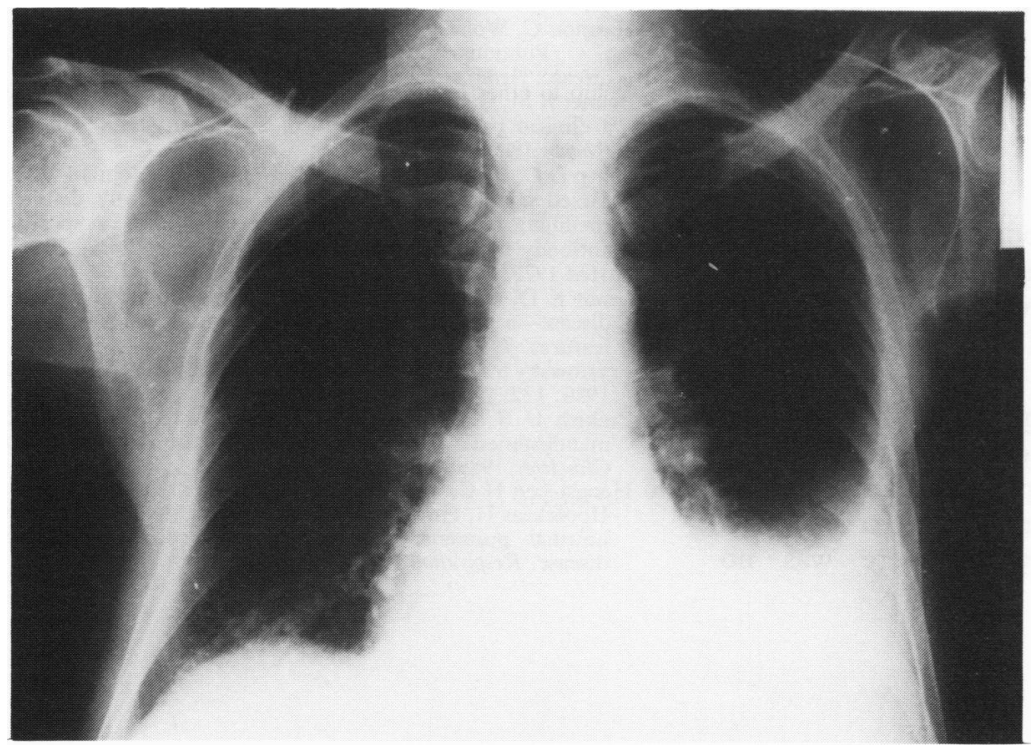

Figure 1 Chest radiograph showing a left sided pleural effusion with normal heart size and no parenchymal findings. normal vital signs. Sclerodactyly of the hands was prominent and Raynaud's phenomenon was induced by cold water. Skin examination showed leathery-like red areas over his arms, face, and chest. Dullness on percussion, decreased tactile fremitus, and breath sounds were noted in the posterior aspect of the left lung. A 3/6 systolic murmur was heard over the fifth intercostal space and mid-clavicular line. The remaining physical examination was normal.

Laboratory examination showed a sedimentation rate of $130 \mathrm{~mm}$ in the first hour. Urine analysis was normal. Haemoglobin was $129 \mathrm{~g} / \mathrm{l}$, packed cell volume $0 \cdot 41$, and white blood cell count $13.5 \times 10^{9} / 1$ with a normal differential. Kidney and liver function tests were normal. The creatinine kinase level was $305 \mathrm{U}$ (normal range 50-100 U). Antinuclear factor was strongly positive and consisted mainly of antibodies to ribonucleoprotein. There was no antibodies to DNA. Thyroid function tests were normal. Arterial blood gases showed $\mathrm{pH} \mathrm{7} 4, \mathrm{PaCO}_{2} 75 \mathrm{mmHg}$ and $\mathrm{PaCO}_{2}$ $37 \mathrm{mmHg}$. A chest radiograph showed left sided pleural effusion and no parenchymal infiltrate (fig 1). A skin test with purified protein derivative $(5 \mathrm{TU})$ was negative. The pleural effusion was an exudate with protein levels of $45 \mathrm{~g} / 1$ and $1 \cdot 5 \times 10^{9} / 1$ leucocytes, $80 \%$ of which were mature lymphocytes with no malignant cells, and negative acid fast stain and tuberculosis culture. The pleural biopsy sample (fig 2) showed an extensive inflammatory lymphoplasmacytic infiltrate affecting the muscle with changes in the muscle fibres. There was fragmentation of single muscle fibres, variation in size, fibre loss, and focal fibrosis. In some foci macrophages were seen ingesting fragments of muscle tubes. No glanulomata nor signs of malignancy were seen.

The muscle biopsy sample from the quadriceps (fig 3) showed foci of necrotic muscle fibres with phagocytosis of the sarcolemma. Other areas showed basophilia of the hyaline contents of the fibres with proliferation of sarcolemmal nuclei. Small aggregates of lymphocytes and mononuclear cells were also seen around necrotic muscle fibres. The bone marrow was normal. A gallium bone scan was also normal. A chest computed tomography scan showed a large left pleural effusion.

The patient was treated with isoniazide and rifampicin for nine weeks with no clinical or radiological response. Treatment with prednisone $(40 \mathrm{mg} / \mathrm{day})$ was then begun with an improvement of the symptoms and partial resolution of the pleural effusion. 


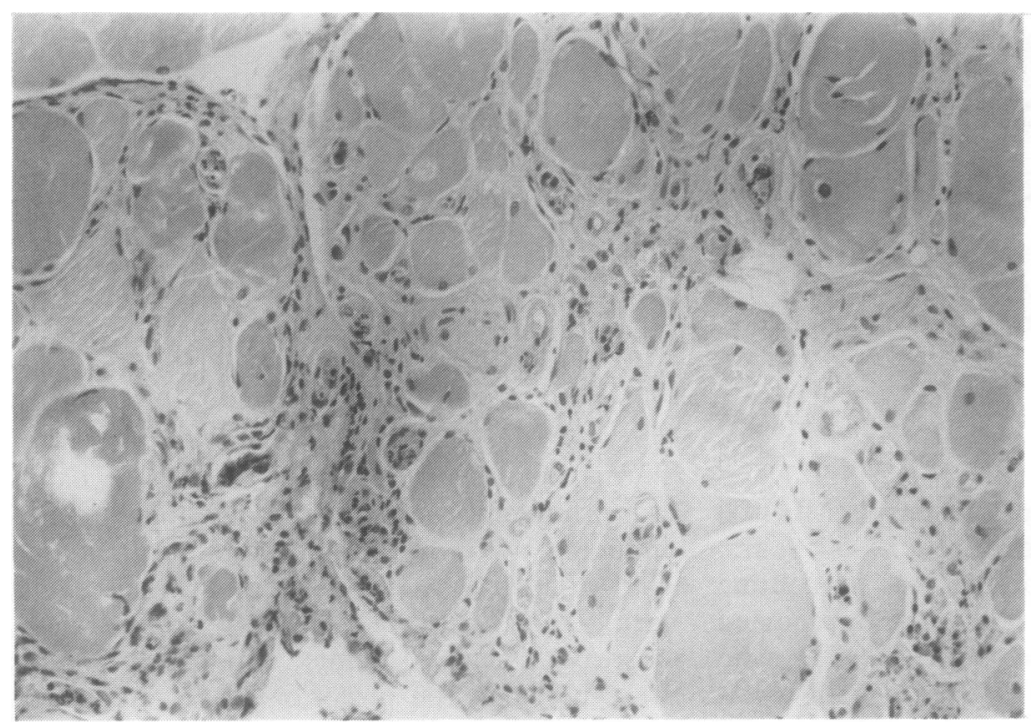

Figure 2 Pleural biopsy sample showing the variation in size and fragmentation of many intercostal muscle fibres. Note areas of fibre loss with fibrosis and extensive inflammatory infiltrate of mainly lymphocytes and plasma cells. Haematoxylin and eosin stain. response to treatment for this disease and the acid fast stains and cultures were negative.

The presentation of MCTD as a large left pleural effusion in our patient is unusual. Pulmonary disease occurs in $25-80 \%$ of patients with MCTD. ${ }^{3-9}$ Sixty five per cent of these patients are asymptomatic; the others may have dyspnoea, chest pain, or cough. Radiologically $85 \%$ of patients with pulmonary disease show bilateral interstitial infiltrates. Small pleural effusions were found in $6 \%$ of patients in one isolated series, ${ }^{9}$ but accompanied pulmonary infiltrates in all patients. Pleural effusion without interstitial pulmonary disease has been reported in one patient. ${ }^{10}$ This and the present report show that pleural effusion can be the presenting and the only lung manifestation of MCTD.

It is possible that the fluid accumulation and the dyspnoea are part of the serositis in this disease, but they could also result from the adjacent inflamed intercostal muscles. The observed improvement of the pleural effusion in response to treatment with glucocorticoids is expected to occur in patients with MCTD, a disease which responds to steroid treatment, and such treatment should be considered in any patient with an unexplained pleural effusion. Another unusual feature of the disease in this patient is the age of onset. Most patients with MCTD are women and the mean age of onset is 31.9 years. $^{12}$

In conclusion the case has been reported of a patient with pleural effusion eventually diagnosed as having MCTD. This case shows the importance of reaching this diagnosis and suggests that MCTD should be included in the differential diagnosis of treatable pleural effusions.

Figure 3 Muscle biopsy sample from quadriceps showing foci of necrosis of the fibres with phagocytosis of the sarcolemma. Haematoxylin and eosin stain.

During follow up over the next six months his plural effusion resolved almost completely, the erythrocyte sedimentation rate decreased to $25 \mathrm{~mm}$ in the first hour, and creatinine kinase decreased to normal concentrations.

\section{Discussion}

The combination of sclerodactyly, chemical and histological myostitis, and a high level of antinuclear factor, most of which was antibodies to ribonucleoprotein led to the diagnosis of MCTD in this patient. Malignancy such as lymphoma or metastatic spread to the pleura are unlikely if the normal computed tomography scans and the negative pleural fluid cytology and tissue biopsy sample results are considered. Tuberculosis is unlikely as there was no

1 Nimelstein S H, Brody S, McShane D, Holman H R. Mixed connective tissue disease: a subsequent evaluation of the original 25 patients. Medicine (Baltimore) 1980; 59: 239-48.

2 Hench P K, Edington T S, Tam E M. The evolving clinical spectrum of mixed connective tissue disease. Arthriti Rheum 1975; 18: 404-8.

3 Sullivan W D, Hurst D J, Harmon E C, et al. A prospective evaluation emphasizing pulmonary involvement in patients with mixed connective tissue disease. Medicine (Baltimore) 1984; 63: 92-8.

4 Harmon C, Wolfe J F, Lillard S, Held C, Cordon R, Sharp G C. Pulmonary involvement in mixed connective tissue disease. Arthritis Rheum 1976; 19: 801-9.

5 Bennet R M, O'Connel D J. Mixed connective tissue disease: a clinical pathological study of 20 cases. Semin Arthritis Rheum 1980; 10: 25-37.

6 Sharp G C, Irvin W S, Tan E M, Gould R G, Holman H R. Mixed connective tissue disease-an apparently distinct rheumatic disease syndrome associated with a specific antibody to an extractable nuclear antigen (ENA). Am $\mathfrak{f}$ Med 1972; 52: 148-52.

7 Grant K D, Adams L E, Hess E V. Mixed connective tissue disease-a subset with sequential clinical and laboratory features. F R Rewmatol 1981; 8: 587.

8 Prystowsky S D. Mixed connective tissue disease. West $\mathcal{f}$ Med 1980; 132: 288-92.

9 Prakish U B S, Luthra H S, Divertie M B. Intrathoracic manifestations in mixed connective tissue disease. Mayo Clin Proc 1985; 60: 813-24.

10 Hoogstecen H C, Van Dougen J J M, Van der Kwast T H, Hooigkaas $\mathbf{H}$, Hilvering $\mathrm{C}$. Bilateral exudative pleuritis, an unusual pulmonary onset of mixed connective tissue disease. Respiration 1985; 48: 164-7. 